\title{
Endoscopic repair of complex pyloroduodenal stenosis resulting from post-transplant lympho- proliferative disorder
}

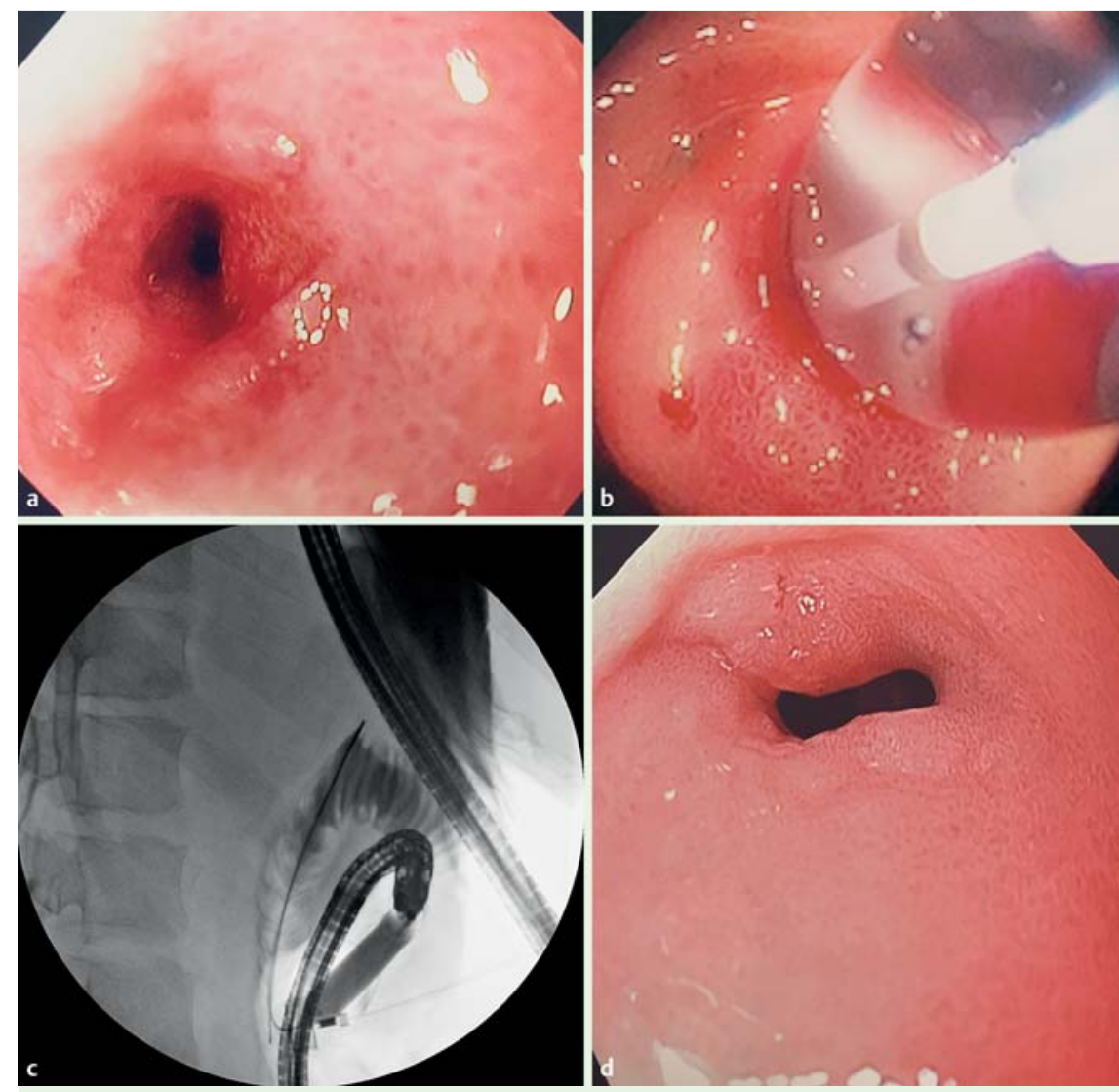

Fig. 1 Complex pyloric stenosis caused by post-transplant lymphoproliferative disorder in a 16-yearold boy. a Stenotic pylorus with pinpoint opening. $\mathbf{b}$ Dilation using a through-the-scope and over-thewire balloon. $\mathbf{c}$ Fluoroscopic guidance of dilation. $\mathbf{d}$ Remaining fibrotic stenosis after several balloon dilations.
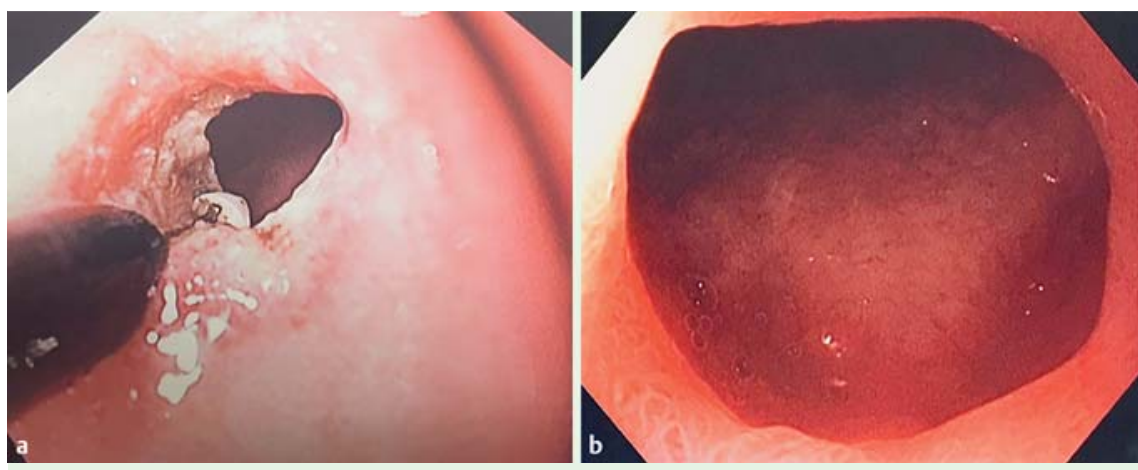

Fig. 2 a Resection of pyloric stenosis using an insulated-tip (IT)-knife. b Appearance at 9-month follow-up after IT-knife resection.

Post-transplant lymphoproliferative disorder (PTLD) is a serious complication after solid organ or allogeneic hematopoietic stem cell transplantation with an incidence rate up to $11 \%$ [1].
While PTLD rarely affects the gastrointestinal (GI) tract [2], in the reported cases it may affect any part of the GI tract, sometimes resulting in stenosis and obstruction [3].

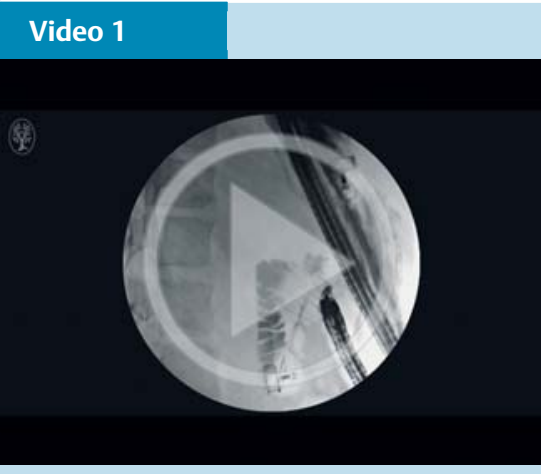

Complex pyloric stenosis caused by post-transplant lymphoproliferative disorder in a 16-yearold boy: endoscopic management.

We present here the case of a 16-year-old boy who had undergone double solid organ transplant, namely a heart transplant at 4 weeks of life because of tricuspid atresia and kidney transplant at 14 years of age because of end-stage kidney injury from calcineurin inhibitors. In June 2013 he developed PTLD that was treated with rituximab for 18 months. However 1 month after the end of the rituximab treatment, the patient presented with vomiting and massive weight loss $(20 \mathrm{~kg})$. Esophagogastroduodenoscopy showed gastric outlet obstruction and a stenotic pylorus with pinpoint opening ( $\boldsymbol{O}$ Fig. $1 \mathrm{a}$, - Video 1). Given the history of PTLD and the patient's poor general status, surgical advice ruled out performance of a gastrojejunostomy and the patient was referred to our unit for a second opinion. An endoscopic solution was offered. Initially, gradual dilations of the pinpoint pyloric opening were performed using both endoscopic and radiologic guidance $(\bullet$ Fig. $\mathbf{1}$ b, - Fig.1c). During the first two sessions the dilations were performed with 6 - and 8-mm biliary dilation balloons, respectively (Cook, Bloomington, Indiana, USA). Subsequent dilations were performed at 2-3-week intervals using larger controlled radial expansion balloons. Despite this aggressive protocol the stenosis remained tight and the patient remained partially symptomatic. The lumen of the stenosis had increased in diameter, but the ring was fibrotic ( $\bullet$ Fig. $1 \mathbf{d}$ ). At this stage it was decided to perform incision 
and resection of the fibrotic ring using an insulated-tip (IT)-knife (Olympus, USA)

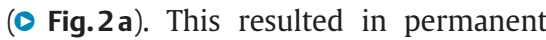
opening of the pylorus. The patient remained asymptomatic and with adequate intake at 9-month follow-up ( $\mathbf{F i g . 2}$ b).

This report is of interest for several reasons. First we present a complication after solid organ transplant, showing that PTLD may lead to gastric outlet obstruction. Second, we show that a staged and graduated endoscopic approach may lead to resolution of this complex gastric outlet obstruction. And finally, we demonstrate that the IT-knife can be used efficiently to perform endoscopic resection of a fibrotic pyloric ring. Although the IT-knife was designed to perform endoscopic submucosal dissection, its ceramic tip and shortended wire appear to be nicely suited to performance of resection of fibrotic rings of the luminal GI tract.

Endoscopy_UCTN_Code_TTT_1AO_2AN
Competing interests: None

\section{Alvaro Martínez-Alcalá, Juan P. Gutierrez, Klaus Mönkemüller}

Basil I. Hirschowitz Endoscopic Center of Excellence, University of Alabama at Birmingham, USA

\section{References}

1 Wasson S, Zafar MN, Best J et al. Post-transplantation lymphoproliferative disorder in heart and kidney transplant patients: a single-center experience. J Cardiovasc Pharmacol Ther 2006; 11: 77-83

2 Gao SZ, Chaparro SV, Perlroth M et al. Posttransplantation lymphoproliferative disease in heart and heart-lung transplant recipients: 30-year experience at Stanford University. J Heart Lung Transplant 2003; 22: 505 514

3 Shitrit D, Shitrit AB, Dickman $R$ et al. Gastrointestinal involvement of posttransplant lymphoproliferative disorder in lung transplant recipients: report of a case. Dis Colon Rectum 2005; 48: 2144-2147
Bibliography

Dol http://dx.doi.org/ 10.1055/s-0042-102961

Endoscopy 2016; 48: E90-E91

(C) Georg Thieme Verlag KG

Stuttgart · New York

ISSN 0013-726X

Corresponding author Klaus Mönkemüller, MD, PhD

Division of Gastroenterology and Hepatology Basil Hirschowitz Endoscopic Center of Excellence Endoscopy Unit, JT 664, 619 19th Street S Birmingham

Alabama 35249

USA

Fax: 01-205-934-6110

klaus1@uab.edu 